\title{
La crisis capitalista mundial, América Latina y Ecuador: ¿socialismo del siglo XXI o neoextractivismo progresista? ${ }^{1}$
}

\author{
The World Capitalist Crisis, Latin America \\ and Ecuador: Socialism of the 21st Century \\ or Progressive Neoextractivism?
}

\section{A crise mundial capitalista, a América Latina e o Equador: ¿socialismo do século XXI ou neoextrativismo progressista?}

\section{Diego Alejandro Ramírez Bonilla ${ }^{2}$}

Asistente docente de la Universidad Nacional de Colombia, Bogotá-Colombia daramirezb@unal.edu.co

Recibido: 31.07 .14

Aprobado: 21.10 .14

l El presente artículo es una versión modificada de uno de los capítulos de la tesis de Maestría en Estudios Políticos Latinoamericanos de Diego Alejandro Ramírez, titulada "Geografía de la acumulación en Ecuador: producción social del espacio en la revolución ciudadana (2007-2013)", actualmente en proceso de desarrollo bajo la dirección del doctor José Honorio Martínez en la Universidad Nacional de Colombia.

2 Politólogo. 


\title{
Resumen
}

Este artículo elabora una caracterización de la crisis capitalista mundial, así como de su más reciente expresión en el sistema financiero luego de la burbuja del 2008 y las repercusiones que manifiesta en las economías latinoamericanas, enfatizando en el análisis de la Revolución Ciudadana de Ecuador y el papel de este país en la economía mundial a la luz de las exigencias del capital transnacional. Se analiza la relación del proceso liderado por Rafael Correa con la valorización del capital a nivel mundial en la crisis económica, así como su conexión con las llamadas potencias emergentes. Finalmente, se aportan argumentos que contradicen la caracterización de este proceso como una vertiente del "socialismo del siglo XXI", resaltando sus características neoextractivistas.

Palabras clave: Crisis Capitalista, Crisis Financiera, América Latina, Ecuador, Neoextractivismo.

\begin{abstract}
This article makes a characterization report on the global capitalist crisis, its most recent expression in the financial system after the bubble of 2008 and its impact on Latin American economies, emphasizing on the analysis of the Citizen Revolution of Ecuador and the role of this country in the global economy in light of the requirements of international capital. The relation between the process led by Rafael Correa and capital appreciation during the worldwide economic crisis, as well as its connection to the socalled emerging powers is analyzed. Finally, there are arguments provided that contradict the characterization of this process as an aspect of "Socialism of the 21st Century", highlighting its features as a form of neoextractivism.
\end{abstract}

Keywords: Capitalist Crisis, Financial Crisis, Latin America, Ecuador, Neoextractivism.

\section{Resumo}

Este artigo visa desenvolver uma caracterização da crise capitalista global e da sua mais recente expressão no sistema financeiro após a bolha de 2008, com impactos nas economias latino-americanas. Se faz ênfase na análise da Revolução Cidadã do Equador e do papel deste país na economia mundial, tendo em conta as exigências do capital transnacional. Será analisada a relação entre o processo liderado por Rafael Correa com a valorização do capital na crise econômica mundial, e sua ligação com as chamadas potências emergentes. Finalmente, salientam-se argumentos que contradizem a caracterização deste processo como uma linha do "Socialismo do Século XXI", particularmente por suas características neoextrativistas.

Palavras-chave: Crise Capitalista, Crise Financeira, América Latina, Equador, Neoextrativismo. 


\section{Introducción}

A raíz del estallido de la crisis financiera del 2008 y las posibles consecuencias que esta puede aún tener en América Latina, resulta apropiado avanzar en una caracterización clara y lo más concisa posible al respecto, abordando la problemática de la crisis desde una perspectiva que dé cuenta de la complejidad de la debacle mundial, la cual trasciende con mucho el simple ámbito financiero. Por este motivo, en el presente artículo se realiza, en un primer momento, un somero recorrido por las principales propuestas teóricas que se han desarrollado desde finales del siglo pasado para explicar la crisis capitalista. De igual manera, se resaltan los efectos que ha producido en América Latina el estallido de la burbuja inmobiliaria. Finalmente, se avanza hacia una reflexión sobre el papel que cumple Ecuador en las dinámicas mencionadas, por ser un país que condensa las numerosas contradicciones emanadas del surgimiento de los llamados gobiernos progresistas latinoamericanos, su relación con diversos movimientos sociales y la puesta en práctica del llamado "socialismo del siglo XXI".

\section{La crisis endémica del capitalismo: el sistema como límite a sí mismo}

La crisis financiera de los Estados Unidos, que comenzó luego del estallido de la burbuja inmobiliaria en el 2008, representó un verdadero punto de quiebre para el análisis económico y el dogmatismo neoliberal, imperante a nivel global tras el desmoronamiento del llamado socialismo realmente existente a principios de la década de 1990. Luego del establecimiento como "teología económica" de las prédicas sobre el libre mercado y sus bondades para acercar a la sociedad a un estadio de crecimiento y bonanza ilimitado, la crisis que estalló con posterioridad a la especulación con los títulos inmobiliarios estadounidenses alertó a diversos sectores políticos, así como a autoridades económicas de todo el mundo sobre las verdaderas implicaciones de un sistema financiero desregulado. Por supuesto, resurgieron de sus cenizas todos los partidarios de la heterodoxia económica, que abogaba por imponer mayores controles al capital financiero, recuperar la participación del Estado en la economía y relanzar el gasto público para solventar "fallos de mercado" como la contracción de la demanda agregada. No obstante, como algunos economistas han hecho notar ${ }^{3}$, estos llamados al orden por parte de las corrientes neokeynesianas o poskeynesianas no consiguen explicar a profundidad o proponer alternativas radicales en relación con la desregulación de las operaciones financieras luego del abandono del patrón oro en 1971. Si bien, para explicar la debacle financiera, dichas corrientes avanzan en otorgar relevancia a factores de política económica que van más allá de la simple irresponsabilidad individual o avaricia de los financistas -elementos psicológicos que los voceros del neoliberalismo tan enfática y reiteradamente resaltan como causantes de la crisis-, aún se quedan cortas a la hora de explicar

3 Nos referimos aquí a aquellos autores vinculados con la crítica a la economía política como Claudio Katz, Robert Brenner, Walden Bello, David Harvey, entre muchos otros. 
las razones de fondo que condujeron al abandono mismo del modelo de acumulación fordista o Estado de Bienestar y el tránsito global que se inició hacia el libre mercado desde los años setenta. A este respecto, las teorizaciones de índole marxista cobran renovada importancia, a pesar de haber perdido terreno en distintos ámbitos académicos luego de presentarse entre estos el abandono generalizado de posturas anticapitalistas desde finales del siglo pasado. La principal razón para el nuevo aire del que goza la producción teórica crítica radica en la rica perspectiva de análisis de la crisis económica que aportan sus planteamientos, como veremos más adelante.

\section{1 "La ley fundamental de la economía moderna": tendencia decreciente de la tasa de ganancia y sobreacumulación de capital}

David Harvey (2007) señala en su libro Espacios del capital, citando a Karl Marx, que al contar como rasgo fundamental de su funcionamiento y razón de ser la "acumulación por acumulación, (y la) producción por producción" (2007, 257), el sistema capitalista se enfrenta a numerosos obstáculos que emanan de su propia tendencia por "producir sin tener en cuenta los límites del mercado" $(2007,257)$ para aumentar incesantemente la ganancia. De esta manera, la competencia intercapitalista destaca como elemento inexorable del sistema, el cual, al tiempo que promueve los abrumadores avances tecnológicos que solo podrían darse dentro de este modo de producción - como el propio Marx reconoce en el Manifiesto Comunista-, también determina su permanente predisposición a crisis periódicas, así como a la devastación ambiental y perversos efectos sociales en cualquier etapa de su ciclo de acumulación. Como consecuencia de esta constatación en el devenir histórico del capitalismo, Marx establece la ley que determina el límite a la acumulación capitalista, esto es, la ley de la caída tendencial de la tasa de ganancia.

La tasa de ganancia es definida por Marx en el tercer tomo de El capital como la porción de plusvalor sobrante con relación al capital invertido: g' = p/ $\mathrm{v}+\mathrm{c}$ (donde g'=ganancia, $\mathrm{p}=$ =plusvalor, $\mathrm{v}=$ capital variable, $\mathrm{c}=$ capital constante). En otras palabras, al tomar el plusvalor producido a través de la explotación de la fuerza de trabajo y dividirlo entre la suma de los gastos que el capitalista realiza en salarios (capital variable o "v") y medios de producción como maquinaria y materias primas (capital constante o "c"), el monto sobrante es lo que el capitalista efectivamente suma a sus ganancias. Esta tasa, sin embargo, expresa una curva decreciente en cada ciclo productivo, pues, como consecuencia de la descarnada competencia entre los poseedores de los medios de producción, estos tienden a aumentar progresivamente la composición orgánica del capital (C.O.C), es decir, la proporción entre capital constante y capital variable, aumentando la tecnificación del proceso productivo -y de esta manera la productividad- mediante el empleo de más y mejores máquinas y menor cantidad de trabajadores. Al hacer esto, se atiende inevitablemente a una superproducción de mercancías que rebasa la capacidad de consumo de las masas — crisis de realización de las mercancías-, potenciándose gracias al desempleo y bajos salarios que los capitalistas mantienen para, paradójicamente, 
conservar sus niveles de ganancia o, mejor aún, impedir que continúen disminuyendo. Estos tipos de crisis - superproducción de mercancías y crisis de realización o subconsumo-, sin embargo, no son más que manifestaciones de una misma crisis de sobreacumulación de capital que es inherente al sistema como consecuencia del decrecimiento de la tasa de ganancia. La sobreacumulación consiste en un excedente tanto de capital - materializado en superproducción de mercancías, capacidad productiva inutilizada y excedente de capital-dinero que no encuentra posibilidades de inversión rentable- como de trabajo — creciente desempleo- (Marx 1959, cap. XIII). De esta forma, la contradicción fundamental del sistema se muestra como una tendencia básica a la abundancia, a la sobreacumulación, nunca a la escasez, derivada de la ley absoluta del capitalismo: la obtención de lucro sobre cualquier otro tipo de consideración (Marx 1999, cap. XXIII).

Partiendo de estos argumentos, el papel de la crisis consiste en "depurar" o "desintoxicar el sistema", "aplicando cierto orden al desarrollo capitalista" que permita ampliar la capacidad productiva y renovar las condiciones para una nueva acumulación (Harvey 2007, 258-259). A través de esta depuración, el sistema logra reabsorber los excedentes tanto en capital-dinero, capital fijo no rentable, sobreproducción de mercancías y trabajo vivo no empleado. De igual manera, a través de las devaluaciones forzosas y el rampante desempleo, se reduce el coste tanto del capital fijo ya existente como de la fuerza de trabajo. Sin embargo, como es lógico suponer, los principales perjudicados a raíz de las crisis capitalistas no abandonarán el mercado de manera dócil, y en cambio desplegarán toda una serie de estratagemas destinadas a impedir el naufragio, lo cual solo resultará en la extensión de la crisis en el tiempo y el espacio.

En virtud de los elementos mencionados, diversos analistas de la corriente de producción teórica marxista ${ }^{4}$ concuerdan en que el sistema capitalista global asiste, desde la década de 1970, a un declive generalizado en la tasa de ganancia, a raíz de la incorporación al mercado mundial de nuevas potencias industriales como Alemania y Japón, quienes luego de avanzar hacia la recuperación de sus economías colapsadas a partir de la Segunda Guerra Mundial, comenzaron a competir con la producción de manufacturas estadounidenses. Junto a esto, el vertiginoso crecimiento de China desde 1978 y de los Cuatro Tigres Asiáticos — Taiwán, Hong Kong, Singapur y Corea del Sur- también contribuyó a incrementar la sobrecapacidad mundial en las industrias, agravada por la contracción salarial a nivel global, lo que generó una crisis de estanflación -estancamiento económico junto a inflación en aumento- en los centros de poder capitalista. Como una manera de contrarrestar la caída tendencial de la ganancia, y especialmente la pérdida de hegemonía estadounidense que asomaba al horizonte luego de la emergencia de nuevos competidores, Estados Unidos desplegó, desde mediados de la década del setenta, las políticas de "ajuste estructural" o reestructuración neoliberal, globalización y

4 En esta perspectiva, aunque con algunos matices entre ellos, encontramos trabajos como los de Brenner (2009); Harvey (2004b); Bello (2008); Duménil y Lévi (2007); Bellamy y Magdoff (2009), entre otros. 
financiarización ${ }^{5}$ a escala planetaria (entrevista Bello 2008). Esta última medida, caracterizada por una fuerte desregulación financiera, fue la estrategia más agresiva de Estados Unidos para mantener su hegemonía frente a Europa, Japón, el Este y el Sudeste asiático. Se constituyó así un "Complejo Wall Street-Reserva Federal-FMI" capaz de "hacer y deshacer muchas economías más débiles a través de la manipulación del crédito y de las prácticas de la administración de la deuda", y de "controlar las instituciones globales y de proyectar un vasto poder financiero alrededor del mundo mediante una red de otras instituciones financieras y gubernamentales" (Harvey 2004b, 108-111). La ventaja fundamental que representó la desregulación financiera fue la de aportar un mercado extremadamente rentable donde invertir los excedentes de capital-dinero que intoxicaban al capitalismo.

De esta manera, la desregulación financiera fue causa de la formación de una burbuja tras otra como consecuencia de la extrema volatilidad de las operaciones en busca de mayor rentabilidad en cada ocasión, desencadenando diversas crisis financieras como la mexicana de 1994-1995, la asiática de 1997-1998 y, por supuesto, la estadounidense de 2008 (entrevista Brenner 2009), que trataremos a continuación.

\section{La crisis financiera del 2008 como manifestación de la crisis estructural}

A la luz de las anteriores disertaciones, la crisis acaecida en el corazón del sistema financiero mundial aparece como una expresión más reciente de la crónica tendencia a la crisis que el capitalismo mundial afronta "por naturaleza", exacerbada desde la década de 1970, en lugar de una consecuencia de la "manía especulativa de unos cuantos funcionarios avaros", como postulan los voceros de la escuela neoclásica.

En el contexto de una baja tendencial de la tasa de ganancia y en un ambiente de disminución de oportunidades de inversión rentable del capital sobreacumulado, la hipertrofia de los flujos financieros obedeció a la necesidad de deshacerse de capitales en proceso de estancamiento, invirtiéndolos en un sector que prometía espectaculares dividendos a partir de la especulación, gracias a la profunda desregulación que sobrevino a este mercado desde la década del setenta. Esto, entre otras cosas, fue lo que ocasionó las llamadas hipotecas subprime y la deuda impagable que tanto en el sector público como privado contaminó la economía estadounidense y que rápidamente derivó en una crisis global debido a la interconexión de los mercados financieros en el mundo. Las políticas de impulso al capital financiero, por lo tanto, representarían una salida al capital estancado en la economía real, como medida desesperada para contener una recesión de titánicas proporciones.

5 La tesis sobre la "financiarización" es una de las más controvertidas al interior del debate marxista contemporáneo, pues no es compartida por diferentes teóricos para explicar la coyuntura económica. Sin embargo, más allá de cuestionarse la evidente hipertrofia financiera de nuestra época o incluso el creciente poder político que adquiere este sector de la economía en el capitalismo actual, el debate principal gira usualmente en torno a la relativa "autonomización" del capital financiero frente al capital productivo. A manera de ejemplo ver Astarita (2008). 
Si hemos de buscar el antecedente más inmediato a la crisis inmobiliaria del 2008, debemos trazar sus orígenes al estallido de la burbuja tecnológica de finales de la década de 1990. Luego del espectacular crecimiento de los valores bursátiles de empresas vinculadas al recientemente creado internet y su consecuente caída al finalizar la fiebre especulativa, el presidente de la Reserva Federal del momento, Alan Greenspan, bajó las tasas de interés a tan solo un $1 \%$ - esta drástica reducción de las tasa de interés, dicho sea de paso, representó una medida de emergencia para frenar la inminente recesión que se veía venir luego del desplome de las acciones punto com-, favoreciendo así la formación de la burbuja inmobiliaria, en la cual el fácil acceso a crédito permitió la especulación en el mercado de finca raíz. Al percatarse de la inmensa oportunidad de generar beneficios a partir de la venta de hipotecas a distintas entidades financieras e inversores, las instituciones hipotecarias terminaron por rebajar sus exigencias para acceder a préstamos por parte de sus clientes, derivando en el establecimiento de tratos hipotecarios con riesgos de impago mucho más elevados que aquellos considerados óptimos, es decir, se otorgaron créditos a familias que no tenían manera de pagarlos a largo plazo. De esta forma, cuando las hipotecas sub-óptimas (o subprime) finalmente resultaron impagables, todos los que participaron en la compra y venta de dichos títulos resultaron afectados.

A lo anterior se le debe sumar el hecho de que desde los setenta, como resultado de la reducción en empleos, salarios y gastos sociales - con la consiguiente contracción de la demanda que esto implicó desde dicha década-, las autoridades económicas estadounidenses buscaron fomentar el consumo a través del crédito tanto público como privado, el primero mediante políticas de tipo "keynesiano tradicional" y el segundo a través de lo que Robert Brenner llama un nuevo tipo de "keynesianismo de precios de activos" (Brenner 2009). Este nuevo tipo de impulso a la demanda agregada para evitar la profundización de la recesión económica, comienza a implantarse con la administración Clinton, durante la cual, como ya se mencionó, la Reserva Federal impulsó el acceso masivo a créditos rebajando las tasas de interés, incentivando al mismo tiempo la inversión en activos financieros: "Al dispararse los precios de los activos, las empresas y familias obtendrían enormes aumentos de riqueza, al menos sobre el papel. Estarían, por tanto, en condiciones de tomar préstamos a una escala titánica, de incrementar infinitamente la inversión y el consumo y, así, conducir la economía" (Brenner 2009).

Debido a que durante toda esta etapa el crecimiento económico estadounidense estaba apoyado tanto en el consumo personal como en el mercado inmobiliario gracias a los préstamos de fácil acceso -consumo personal a través de la reamortización de hipotecas y otros tipos de endeudamiento e inversión en finca raíz a través de facilidades de crédito- resulta evidente, como señala el citado autor, que al momento de estallar la burbuja especulativa en este último terreno toda la economía del país se viese perjudicada.

Si bien es necesario realizar un análisis precavido sobre el papel de las finanzas en el capitalismo contemporáneo y en la subsecuente crisis a la que se 
asiste en la actualidad ${ }^{6}$, recibiendo con cautela las tesis sobre la financiarización de la economía, la "autonomización de los mecanismos financieros en relación con sus bases en la producción" (Duménil y Lévy 2007, 141) e incluso un más prudente argumento sobre la sola primacía del "capital monopolista financiero" (Bellamy y Magdoff 2009), no es posible ignorar el desarrollo astronómico que han tenido los mecanismos y operaciones financieras en el momento actual, llegando incluso a desdibujar en algunos países la línea entre capital productivo y capital financiero (Duménil y Lévy 2007). De igual manera, las inigualables ganancias en este sector de la economía también permiten observar un salto cualitativo y cuantitativo de este respecto a cualquier etapa precedente de desarrollo capitalista?.

Lo que quizás no admita discusión, tomando en cuenta la creciente pauperización de las masas trabajadoras al tiempo que ocurre un espectacular enriquecimiento de una pequeña élite mundial —incluso en el contexto de una crisis económica generalizada-, es que el incremento de las ganancias del capital financiero en las últimas décadas corresponde directamente a una expropiación de los fondos de consumo de los trabajadores hacia las arcas de la clase capitalista. De igual manera, el creciente protagonismo del capital financiero en todos los aspectos de la vida social, consolidando una subsunción total de la vida humana a las lógicas capitalistas, demuestra una evidente transformación de las lógicas de poder desplegadas por este sistema, partiendo de la simple "sujeción anatómica" de la población hacia una reglamentación de su vida cotidiana, incluyendo en esta aspectos tanto biológicos, como anatómicos y psicológicos. Es, verdaderamente, la constitución del biopoder para garantizar la perpetuación de la acumulación de capital (Lucarelli 2009).

La crisis en tránsito rebosa las características de una simple coyuntura económica, alcanzando una dimensión estructural. Estos tipos de crisis, en palabras del cubano Eugenio Espinosa, "podrían definirse como aquellas que conducen a cambios en la acumulación, tienen una duración de 5 a 10 o 20 años, suelen marcar cambios de época y podrían vincularse a los ciclos largos de acumulación" (Espinosa 2012, 125). De igual forma, estas crisis suelen comenzar en una economía y extenderse al conjunto del sistema mundial, produciendo "impactos sobre lo político: cambios en los partidos, cambios de gobierno, en el régimen político, en el Estado" (Espinosa 2012, 125). Si a lo anterior le agregamos las crisis energética, ambiental, climática, alimentaria e hídrica con las que se mezcla la debacle económica, nos encontramos ante una verdadera crisis civilizatoria sin precedentes en la historia humana (Vega 2009).

Todos estos elementos, como era de esperarse, produjeron profundos impactos en la realidad latinoamericana, asistiendo el continente a "cambios en la acumulación capitalista, del neokeynesianismo-desarrollismo, al neoliberalismo; al neokeynesianismo-neodesarrollismo. En lo político se evoluciona de las Dictaduras

6 Es pertinente recordar que la relación parasitaria y contraproducente entre el capital financiero y el capital productivo se encuentra presente en este modo de producción desde sus etapas más tempranas, como el mismo Marx ya lo señalaba en su momento.

7 El debate sobre la financiarización, sin embargo, rebasa tanto la intención como las posibilidades del presente artículo. 
Militares de seguridad nacional desarrollistas a las dictaduras militares neoliberales, a gobiernos civiles neoliberales, a gobiernos civiles neodesarrollistas, a las revoluciones constituyentes, al socialismo del siglo XXI" (Espinosa 2012, 126).

\section{América Latina: crisis, reforma y cambio político}

América Latina es el territorio donde se prueba por primera vez el experimento neoliberal a través del golpe del general Augusto Pinochet en Chile. A raíz de sus excelentes resultados para el capital transnacional, este modelo económico fue luego implantado por los gobiernos de Margaret Thatcher, en el Reino Unido, y Ronald Reagan, en los Estados Unidos, para luego propagarse por el resto del mundo. Unos años más tarde, como consecuencia de la crisis de la deuda extendida por la región ${ }^{8}$, los gobiernos tanto civiles como militares del continente se encargaron de imponer el neoliberalismo de manera generalizada.

Las consecuencias sociales de la apertura económica, como la privatización y la reducción en gastos sociales, condujo a fuertes revueltas en buena parte del continente, teniendo expresiones tan paradigmáticas como el Caracazo en Venezuela en 1989. De igual manera, en la década siguiente, a pesar de la caída del bloque soviético, algunos proyectos políticos de izquierda comenzaron a recobrar fuerza en distintos territorios, alimentándose de la entrada en escena de outsiders -dirigentes políticos que sin ser políticos profesionales o haber participado en política anteriormente, acceden a cargos públicos a partir de un contundente apoyo social y electoral, como Lula Da Silva en Brasil, Hugo Chávez en Venezuela o Evo Morales en Bolivia- y movimientos sociales que anteriormente no influían de manera determinante en el devenir político de sus respectivos países, como es el caso de los movimientos indígenas en Bolivia y Ecuador.

En estas circunstancias, el primer gobierno en la región en enarbolar la bandera antiimperialista, luego de la declinación del discurso revolucionario marxista en el mundo, fue el del venezolano Hugo Chávez, elegido popularmente en 1999, quien recuperó en 2005 el debate sobre la alternativa socialista frente al neoliberalismo y la posibilidad de adecuar las teorías y prácticas revolucionarias a la realidad concreta del siglo XXI. A este le siguieron las posesiones de mandatarios como Lula da Silva en Brasil (2003), Néstor Kirchner en Argentina (2003), Tabaré Vázquez en Uruguay (2005), Evo Morales en Bolivia (2006), Rafael Correa en Ecuador (2007) y Fernando Lugo en Paraguay (2008), aunque este último sería destituido de su cargo en 2012. Entre estos gobiernos, los de Venezuela, Bolivia y Ecuador han destacado por su mayor enfoque hacia la reducción de la pobreza y la desigualdad, así como por su abierta crítica a la injerencia de potencias extranjeras como Estados Unidos en el continente, además de autodenominarse como adherentes al "socialismo del siglo XXI". Los gobiernos de Brasil, Argentina y Uruguay, a pesar de mostrar claras diferencias respecto a la derecha tradicional en términos de gasto social y relación con las potencias extranjeras,

8 Colombia vendría a ser una excepción particular. La crisis de la deuda no afectó al país, en gran parte gracias a los dineros del narcotráfico que incrementaron su ingreso a la economía colombiana durante la década de 1980. Sin embargo, al igual que sus demás pares latinoamericanos, el país aceptó dócilmente las políticas de liberalización económica dictadas por el Fondo Monetario Internacional desde la presidencia de Virgilio Barco (1986-1990). 
no han logrado demasiados avances en reducir la pobreza, la desigualdad o la dependencia al capital extranjero. Tampoco han ganado protagonismo por cuestionar el propio sistema capitalista, más allá de esporádicas prédicas por un "capitalismo de rostro humano".

Debido a la enorme dificultad de realizar una caracterización profunda de cada uno de estos procesos mencionados, y más aún de agruparlos dentro de categorías que más o menos den cuenta de sus enormes diferencias internas, salvo en el caso de Ecuador que abordaremos más adelante, nos referiremos a estos gobiernos que provienen de sectores alternativos a la derecha tradicional con el término genérico de "progresistas".

\subsection{La crisis financiera del 2008 en América Latina}

Avanzados estos nuevos procesos políticos, cada uno con sus logros, deficiencias y contradicciones internas, la crisis financiera hizo presencia en el continente, aunque con características obviamente diferentes a las presentadas en regiones como EE.UU., Europa y Asia.

Las consecuencias de la crisis estructural que se viene presentando desde los setenta en América Latina han sido bastante evidentes y generalizadas, aunque no pueda decirse lo mismo aún de las consecuencias de la crisis del 2008. Sin embargo, el hecho de que en América Latina no hayan ocurrido los nefastos episodios vividos durante los últimos años en países como España, Grecia, Portugal o Irlanda, no quiere decir que nuestras economías hayan estado o sigan estando completamente blindadas respecto a una futura expansión de la crisis mundial.

De hecho, por lo menos tres factores demuestran la fragilidad de nuestro continente frente a los desajustes experimentados en la economía global. En un primer momento de la crisis, durante el 2008, la escasez de liquidez en las economías del primer mundo devino en fugas de capital de los países latinoamericanos hacia Estados Unidos y Europa. De igual manera, al ser América Latina también protagonista de la crisis de sobreproducción de mercancías, industrias como la automotriz se vieron afectadas debido a la contracción de la demanda de los países afectados por la burbuja financiera. Finalmente, el abaratamiento de materias primas - como consecuencia igualmente de la reducción en la demanda de estas por parte de las economías centrales- con consiguientes recesiones en los países protagonistas de una reprimarización de su economía, aumentó las cifras de desempleo y desigualdad social (Katz 2009, 139).

Luego del primer momento de shock, con los augurios más negativos sobre el desenlace de la crisis para nuestras latitudes a la orden del día, el efecto

9 Entre los intentos de caracterización realizados en torno a estos gobiernos, destacan apelativos como "neodesarrollistas y nacional radicales" o "centroizquierda e izquierda" (Katz 2007; Estrada 2012). Sin embargo, para no desviarnos del objetivo principal del presente trabajo, recurriremos al más genérico término progresistas, como lo entiende el uruguayo Eduardo Gudynas: "(la) izquierda latinoamericana es muy variada, con diferencias notables entre Evo Morales en Bolivia y Lula da Silva en Brasil, o Rafael Correa en Ecuador y el Frente Amplio de Uruguay. Estas distintas expresiones han sido rotuladas como izquierdas socialdemócrata o revolucionaria, vegetariana o carnívora, nacional popular o socialista del siglo XXI, y así sucesivamente. Pero estos gobiernos, y sus bases de apoyo, [...] comparten [...] la idea de progreso como elemento central para organizar el desarrollo, la economía y la apropiación de la Naturaleza" (Gudynas 2013). 
financiero de la crisis no se mostró significativo, llevando a algunos analistas como el argentino Claudio Katz a afirmar la naturaleza más comercial que financiera de esta para nuestro continente. Sin embargo, a este respecto, el fenómeno de la contracción de la demanda en centros capitalistas mundiales, tan negativa para las exportaciones latinoamericanas, se vería parcialmente contrarrestado por el aumento de esta en países como India o China (Katz 2010, 4).

No obstante, una de las principales amenazas que versan sobre las economías latinoamericanas luego de pasado el primer momento de crisis, consiste en la entrada, luego de 2009, de numerosos capitales golondrina a nuestros mercados financieros, los cuales pueden propiciar la creación de nuevas burbujas financieras esta vez en nuestro territorio. En caso de cumplirse y extenderse esta amenaza, América Latina no estaría en condiciones de hacerle frente al no contar con los mismos recursos del centro capitalista (Katz 2010, 4).

Finalmente, en cuanto a los elementos de política económica que contribuyeron a la contención de la crisis financiera mundial en América Latina, destacan las medidas desarrolladas por los gobiernos progresistas, encaminadas a regular las entradas y salidas de capital, financiar proyectos de infraestructura, estimular el crecimiento económico a través de políticas anticíclicas, contener la deuda pública y privada, estimular el empleo y, hasta cierto punto, el mercado interno y la puesta en práctica de políticas sociales enfocadas a la reducción de la pobreza y la desigualdad (Espinosa 2012, 136). Sin embargo, tomando en cuenta la evidente dependencia de nuestras economías, cualquier tipo de políticas de contención de la debacle financiera implantadas en América Latina, estarán necesariamente limitadas por nuestro acople con los centros de poder económico mundial.

\subsection{El imperio y las nuevas potencias en la geopolítica continental}

Durante las últimas décadas ha sido común, dentro de distintos centros de pensamiento así como para ciertos estrategas políticos, vaticinar la inminente declinación en el poder de los Estados Unidos para garantizar sus intereses nacionales a nivel mundial. La tesis sobre la "decaída en la hegemonía estadounidense" (Borón 2013) ha cobrado relevancia a la luz no solo de la reciente crisis surgida en su corazón financiero, sino también luego de fiascos militares como el resurgimiento de sectores armados abiertamente antiestadounidenses en Irak y otras regiones víctimas del intervencionismo del imperio. En nuestro continente, desde la consolidación de proyectos como la Unasur o el Mercosur, así como la pérdida de protagonismo del gigante del norte en la OEA, la idea de un mundo multipolar se ha fortalecido en los análisis políticos contemporáneos. La entrada a nuestro territorio de masivas inversiones chinas desde la primera década del presente siglo ${ }^{10}$, así como la expansión de inversiones brasileñas por buena parte de nuestros países vecinos, han contribuido a plantear una suerte

10 A este respecto, Lin Yue, investigador del Centro de Estudios de Asia Central de la Universidad Autónoma de Madrid, aporta interesantes datos sobre la inversión extranjera directa de China en América Latina. 
de "traspaso de poder global" hacia el gigante de Asia o a rescatar teorizaciones sobre el papel subimperialista ${ }^{11}$ que Brasil aún cumple específicamente en Sudamérica, como hace años sería planteado por Ruy Marini.

Sin embargo, aunque no pueda desconocerse la importancia de la entrada en escena de las denominadas potencias emergentes en la geopolítica latinoamericana, es claro que Estados Unidos continúa jugando un papel principal en la administración del continente. Como resalta Atilio Borón en su libro América Latina en la geopolítica del imperialismo, citando los importantes trabajos investigativos de la mexicana Ana Esther Ceceña y la peruana Mónica Bruckmann -la primera, enfocada en las áreas de riqueza natural estratégica del continente y las zonas de presencia militar estadounidense en el mismo; la segunda, sobre los minerales estratégicos para EE.UU. y los países latinoamericanos que los exportan-, Estados Unidos no ha ahorrado esfuerzos por asegurar su presencia en aquellos países donde se encuentran los principales recursos naturales de la región, sean agua, petróleo, minerales o incluso posiciones militares estratégicas. Si bien es cierto que las políticas antiimperialistas de algunos gobiernos progresistas han dificultado en los últimos años el acceso a sus recursos por parte del imperio del norte, la reacción imperialista tendiente a derrocar a estos gobiernos ha sido constante -intentos de golpes de estado en Bolivia, Ecuador o Venezuela, este último aún en curso- (Borón 2013).

La entrada en escena de China, por lo demás, no ha suscitado un verdadero conflicto con los intereses norteamericanos o de otras potencias económicas interesadas en la extracción de recursos del continente, por lo cual más que hablar de una disputa interimperial entre el país asiático y las potencias de Occidente —o algún tipo de disputa parecida a aquellas vividas durante el periodo pre y pos Primera Guerra Mundial- podríamos más bien estar atestiguando una entrada de las potencias emergentes al imperialismo colectivo de posguerra (Katz 2011).

En el caso brasileño, es evidente la transformación cualitativa del poder que este "gigante del Sur" ejerce sobre el territorio subcontinental, impulsando proyectos como la Integración de la Infraestructura Regional Sudamericana (IIRSA) destinados a integrar a las economías subcontinentales en torno a su propio poderío. Este proyecto, sin embargo, aún de la mano de los gobiernos progresistas de Lula da Silva y Dilma Rousseff, continúa con la pretensión de sus antecesores derechistas de incorporar "al conjunto de la región al mercado y al empresariado mundiales", aunque para hacerlo esta vez impulse una primera integración subordinada, y forzada, de los países sudamericanos a la economía brasileña (Zibechi 2012).

De igual manera, como afirma Katz y que bien se puede constatar más allá de la teoría examinando las relaciones diplomáticas, económicas e incluso militares, entre Brasil y Estados Unidos - sin tomar en cuenta los halagos que tan frecuentemente han colmado el discurso oficial de ambos países al referirse el uno al otro-: "Brasil busca ocupar los espacios creados por la crisis de dominación estadounidense. Pero aspira a cumplir este rol sin chocar con la primera potencia. Tratará de saltar un escalón dentro de la coordinación hegemónica que

11 Subimperialismo entendido como la emergencia de una nueva potencia con asociación subordinada a los Estados Unidos, lo que se expresa a través de la expansión de empresas brasileñas al exterior como resultado de la estrechez de su propio mercado interno (Katz 2009). 
ha prevalecido desde la posguerra. Las clases dominantes brasileñas pretenden jugar un rol más visible, pero al mismo tiempo más integrado al imperialismo colectivo", por lo cual, más allá de presentar una alternativa a la dominación imperialista en el continente, o tan siquiera un refrescante aumento en la autonomía regional, lo que estaría por gestarse sería una asociación entre las élites locales y las élites transnacionales, aumentando así la opresión sobre las clases subalternas (Katz 2009, 153).

A modo de síntesis, América Latina, antes que haber disminuido su importancia para los Estados Unidos como para considerar una reterritorialización de su dominio, no ha hecho otra cosa que aumentar su significación para la "valorización del capital hegemónico", especialmente en virtud de los nuevos desarrollos tecnológicos y comunicacionales que otorgan inusitada relevancia a recursos naturales que hasta hace solo unas décadas no representaban mayor interés para el proceso de acumulación. Es así como los hidrocarburos, minerales, biodiversidad, fuentes hídricas y posibilidades de control geopolítico a través de la construcción de infraestructura y de bases militares, otorgan al continente su carácter de nuevo espacio de valorización (Jiménez 2012, 270).

\section{Ecuador ante la crisis mundial}

El proceso político iniciado en Ecuador en el 2007 merece especial atención a la luz de las acontecimientos anteriormente relatados, al resultar este la combinación de múltiples elementos, algunas veces de carácter verdaderamente revolucionario, otras de tinte regresivo, pero siempre riesgosamente contradictorios. Por este motivo, resulta interesante analizar las dinámicas políticas, económicas y sociales que se presentan en Ecuador desde la posesión de Rafael Correa y la relación que estas han tenido con la crisis mundial capitalista y una de sus últimas manifestaciones, la crisis financiera de 2008.

\subsection{Emergencia de la Revolución Ciudadana, movilización social y promesas socialistas}

En las elecciones presidenciales de Ecuador del año 2006, Rafael Correa Delgado, perfilado como fuerte opositor del modelo neoliberal imperante, alcanzó el control del Ejecutivo a través de la constitución de un movimiento político creado en torno a su figura, denominado Alianza PAIS, que se instaló como principal fuerza política a partir de un discurso antipartidista y antineoliberal, que hacía suyas a la vez, varias de las históricas reivindicaciones del movimiento indígena ecuatoriano como el reconocimiento de las diferentes nacionalidades indígenas y la defensa del territorio. En este sentido, tras asumir el poder en enero de 2007, el presidente Rafael Correa cumplió una de sus principales banderas de campaña que consistió en la convocatoria a un Referendo en abril de 2007 para la realización de una Asamblea Nacional Constituyente con plenos poderes. El texto producto de dicha Asamblea, la Constitución Política del Ecuador de 2008, además de definir al Estado ecuatoriano como "plurinacional e intercultural" (Ospina y Lalander 2012, 119) también incorporó a nivel constitucional el concepto de "Sumak Kawsay" o "Buen Vivir", concepto indígena que 
radicalizó el tema de la protección ambiental hasta el punto de romper con la visión tradicional de desarrollo y crecimiento económico capitalista, para sustituirla por un nuevo "paradigma" centrado en una nueva relación armónica con la naturaleza, pasando esta a ser reconocida como sujeto(a) de derechos (Ospina 2012, 113). Adicionalmente a la aprobación de esta revolucionaria Carta Magna y luego de ser reelecto en las elecciones de abril de $2009^{12}$, el gobierno Correa redactó el Plan del Buen Vivir 2009-2013, en donde se estipula como objetivo de la administración superar la dependencia del extractivismo primario-exportador para consolidar un modelo de Socialismo del Siglo XXI centrado en el aprovechamiento de la biodiversidad, el conocimiento y el bioturismo, enfocados a la transformación del Ecuador en una "biópolis eco-turística", lo que permitiría superar la dependencia de exportación de materias primas (Ospina 2012, 129) ${ }^{13}$. No obstante, luego de promulgar este tipo de legislación claramente revolucionaria, la administración Correa se encargó de fomentar la aplicación de nuevas normas legales que permitieran el desarrollo de actividades mineras y petroleras de manera unilateral, sin pasar por los mecanismos de consulta previa estipulados constitucionalmente (el mejor ejemplo de esto es la Ley Minera de 2009 $9^{14}$ ). De esta forma, la divergencia y abierto antagonismo entre el gobierno de Rafael Correa y el movimiento indígena ecuatoriano, representado principalmente por la Confederación de Nacionalidades Indígenas del Ecuador (CONAIE), se hizo evidente $\mathrm{e}^{15}$, llegando el presidente a acusar a las posturas críticas frente a sus políticas de impulso al desarrollo minero y petrolero como "izquierdismo, ecologismo e indigenismo infantil" (Ramírez 2010, 98).

\subsection{La crisis financiera en el país andino}

$\mathrm{Al}$ igual que el resto de las economías latinoamericanas, al consistir la mayor parte de su PIB en los ingresos derivados de la exportación de materias primas, Ecuador también se vio afectado - al menos temporalmente- por la disminución en el precio internacional de estas. De esta manera, el desplome en el precio de su principal commodity, el petróleo, derivó en una fuerte disminución de los ingresos nacionales desde junio de $2008^{16}$. De igual manera, el aumento en los niveles de desempleo, así como el déficit fiscal y comercial (los llamados zación de elecciones generales ese año.

Este nuevo modelo de desarrollo - marcadamente diferente de los anteriormente aplicados en Ecuador según sus proponentes - sería calificado como biodesarrollista por el propio ministro de la Secretaría Nacional de Planificación y Desarrollo (SENPLADES), René Ramírez, uno de los principales proponentes del Plan del Buen Vivir (Breda 2009).

Clavero (2011).

Dos acontecimientos que han resultado ejemplares de este distanciamiento y abierto antagonismo han sido las protestas desarrolladas desde 2009 frente a la Ley de Aguas, mediante la cual el gobierno nacional pretendía regular el acceso al agua, y la Marcha Plurinacional por el Agua, por la Vida y la Dignidad y la Dignidad de los Pueblos llevada a cabo en marzo de 2012, en donde además de la defensa del agua, se sumaban el rechazo a la megaminería y a la criminalización de la protesta social. En ambos acontecimientos, la CONAIE ha sido uno de los actores principales (Dávalos 2012; Mena 2012).

16 Para una visión general sobre la caída a nivel global del precio de las materias primas durante el 2008, ver International Monetary Fund (2004). 
déficits gemelos) ${ }^{17}$, también evidenciaron las consecuencias de la crisis financiera en la economía ecuatoriana.

Otra de las principales fuentes de ingresos del Ecuador, las remesas provenientes de Estados Unidos y España (nuevo hogar de la mayor parte de emigrantes del país), se redujo masivamente, consecuencia de la caída —en las economías mencionadas - de los niveles de empleo en sectores como la construcción, donde se desempeñaba la mayoría de ciudadanos expatriados.

Finalmente, la dolarización de la economía ecuatoriana representó (y continúa haciéndolo) uno de los mayores limitantes frente a las posibilidades de desarrollar políticas anticíclicas de carácter monetario o cambiario para contener algunos efectos de la crisis. De igual manera, luego de una revalorización del dólar a la que se asistió en 2009, las exportaciones ecuatorianas resultaron afectadas (Acosta 2009).

Sin desconocer los factores mencionados, en sintonía con el impacto de la crisis en otros países de la región, esta no tuvo, o no ha tenido hasta el momento, consecuencias tan desastrosas sobre la economía de Ecuador, siendo compensados factores como la disminución de inversión por parte de las potencias económicas de Occidente con la entrada en escena de países como China.

\subsection{Estados Unidos, China y Brasil: la nueva forma de dominación}

El papel de Estados Unidos en Ecuador recibió una fuerte sacudida ante la posesión de Rafael Correa como presidente y la emergencia de la Revolución Ciudadana como proyecto antagonista al modelo de liberalización económica impuesto desde Washington sobre todo el continente. Actuaciones como la no renovación del tratado que mantenía en funcionamiento la base de Manta o el decidido fomento - al menos inicial- del presidente Correa a procesos de integración regional como la Alternativa Bolivariana para América Latina y el Caribe (ALBA), fueron motivo de serios distanciamientos diplomáticos entre ambos gobiernos. En este contexto tanto China como Brasil aumentaron las negociaciones e inversiones con el gobierno de Carondelet.

En estas nuevas relaciones, la extracción minera cobró una importancia trascendental, especialmente en relación con las inversiones chinas. La importancia que adquirió este sector de la economía especialmente durante el gobierno Correa, es claramente expuesta por Alberto Acosta y William Sacher:

\footnotetext{
Según los datos producidos por las propias empresas mineras [...] los metales presentes en los yacimientos más grandes del país representarían 270.000 millones de dólares (una cifra que conviene comparar a los 70.000 millones provenientes del petróleo, la principal fuente de ingresos del país). La mayor parte de este monto viene del cobre y el oro, debido a sus altos precios por tonelada. Es sin duda por esta razón que el gobierno actual defiende intensamente la minería metálica a gran escala. Sin embargo, cabe señalar que estas cifras son altamente susceptibles a los mercados internacionales. En el transcurso de apenas dos semanas entre finales de julio e inicios
}

17 El déficit fiscal repercutiría negativamente sobre la inversión pública, mientras que el déficit comercial implicaría una reducción drástica de los ingresos no petroleros del país (Acosta 2009). 
de agosto de 2011, el valor total de los yacimientos ecuatorianos de cobre cayó de 201.250 millones a 191.800 millones de dólares a raíz de la caída de los precios de este metal (Sacher y Acosta 2012, 73).

En relación con lo anterior, el gobierno del presidente Correa impulsó cinco proyectos estratégicos de minas a cielo abierto: Mirador (Morona SantiagoZamora Chinchipe) y Panantza-San Carlos (Morona Santiago) de cobre; Río Blanco (Azuay), Quimsacocha (Azuay) y Fruta Norte (Zamora Chinchipe) de oro. Tres de estos cinco proyectos se encuentran adjudicados a empresas chinas (Mirador, Panantza-San Carlos y Río Blanco), uno a una empresa canadiense (Quimsacocha) y otro (Fruta Norte) abandonado el 10 de junio de 2013 por la canadiense Kinross y retomado por Fortress Minerals Corp, del mismo país, en octubre de 2014. No obstante, de los cinco proyectos, solo Mirador fue firmado para comenzar el proceso de explotación a finales del $2013^{18}$.

El proyecto Mirador, ubicado en la provincia de Zamora Chinchipe (suroriente ecuatoriano), destaca no solo por ser la más grande mina a cielo abierto que tendrá Ecuador, sino por las dinámicas de despojo de tierras que se vienen presentando en sus inmediaciones para consolidar la puesta en marcha de la explotación cuprífera. Allí, la empresa Ecuacorriente S.A., controlada por la China Railway Construction Corporation (CRCC) ha llevado a cabo, sobre los pobladores de San Marcos, negociaciones fraudulentas de títulos de tierras, desalojo forzado de campesinos que no poseían títulos oficiales de propiedad, e incluso amenazas y acciones abiertamente terroristas de amedrentamiento sobre los habitantes del lugar para que abandonen sus viviendas y dejen el lugar en manos de la empresa china (Comisión Ecuménica de Derechos Humanos 2014).

En el caso de Brasil, luego de la expulsión por parte del presidente Correa el 23 de septiembre del 2008 de la constructora Norberto Odebrecht ${ }^{19}$, así como de la salida de Petrobras en 2010, los contratos de inversión entre ambos países se han enfriado, salvo en el caso de la puesta en marcha de la IIRSA, donde se han presentado grandes avances en su construcción. En este aspecto, el proyecto de mayor envergadura en términos de la adecuación del país a la integración suramericana propuesta, corresponde al Eje Manta-Manaos, parte del eje multimodal que pretende la conexión interoceánica a través del río Amazonas. Dentro de esta estrategia global, la inauguración en 2011 del Tramo Fluvial por el río Napo, se perfila como el más reciente avance en la consecución de dicho propósito, obteniendo financiación por parte del BID y del propio gobierno brasileño ${ }^{20}$.

En ambos casos, como se ha visto, tanto los capitales provenientes de China y Brasil -con mayor fuerza en el primer caso, luego de los choques mencionados entre el gobierno Correa y las empresas brasileñas- han desarrollado dinámicas que bien podrían caracterizarse como acumulación por desposesión (Harvey 2004a; 2004b), para asegurar las ganancias de sus negocios extractivistas.

La Hora (2012); Portal Minero (2011); Araujo (2013); AGN (2012); FETRALPI (2012); Sosa (2013); Ministerio de Recursos Naturales No Renovables (2014).

19 Motivada por reiterados abusos en términos legales y financieros así como irregularidades técnicas, sin mencionar los reiterados abusos laborales y ambientales documentados en regiones indígenas y amazónicas por parte de la empresa (Zibechi 2012).

El Ciudadano (2011); Portal Puerto de Manta, Ecuador (2012). 
Ante este panorama de inserción de estos dos países en la realidad política, económica y social de Ecuador, cabe preguntarse si la imperiosa necesidad de reducir la pobreza en los países latinoamericanos y los loables esfuerzos de los gobiernos progresistas en este sentido a partir de la redistribución de la renta del extractivismo, implica la aceptación ciega e incuestionada de dinámicas de abierto despojo y opresión sobre los pobladores de las áreas donde se desarrolla la explotación minera o petrolera.

\section{Disertaciones finales: ¿ socialismo del siglo XXI o neoextractivismo progresista?}

A partir de la toma de investidura por parte del presidente Correa, su mandato se ha enfocado en la ineludible necesidad de aplicar políticas redistributivas del excedente extractivista a través del asistencialismo estatal, garantizando ciertas mejoras en la situación de pobreza extrema en el país, aunque sin modificar sus causas estructurales. No obstante, debido a la ausencia de una industria ecuatoriana que pueda asumir los elevados costos de dichas políticas sociales, la alternativa asumida por el gobierno de Carondelet, como se planteó anteriormente, se ha basado en la continuación del modelo de exportación de materias primas — "profundizarlo para superarlo", según reza la propuesta del Ejecutivo ecuatoriano-, incentivando la inversión de capital extranjero, especialmente de dos de las denominadas potencias emergentes: Brasil y China.

Tomando en cuenta antecedentes como la postura del gobierno frente a la disidencia social a sus políticas y, sobre todo, el aumento en el impulso a la extracción minera y petrolera —con sus respectivas consecuencias en términos de violación a los Derechos Humanos de comunidades indígenas y campesinas- ${ }^{21}$, no parece desacertado calificar al modelo ecuatoriano de la Revolución Ciudadana como un "neoextractivismo progresista" (Gudynas 2009, 194) enfocado principalmente hacia la superación de las políticas privatizadoras del neoliberalismo, aumentando el papel del Estado tanto en la extracción de recursos como en la ampliación de planes de asistencia social, pero manteniendo en última instancia el proyecto económico dominante en la región, que garantiza la satisfacción de las necesidades del gran capital transnacional de apropiación de recursos naturales (Stolowicz 2011), teniendo como correlato, al igual que ocurre en los demás regímenes "progresistas" latinoamericanos, una inserción subordinada de la economía de este país suramericano en el mercado mundial (Gudynas 2009, 198), características diametralmente opuestas a las de un proyecto auténticamente socialista.

Si entendemos el neoextractivismo ecuatoriano — similar al desarrollado por algunos homólogos latinoamericanos del presidente Correa- como una expresión de las nuevas dinámicas internacionales de circulación del capital, podemos intuir

21 A este respecto, el ex ministro de Correa, Alberto Acosta, ahora abierto opositor del gobierno, menciona: "Perversamente muchas empresas estatales de las economías primario-exportadoras (con la anuencia de los respectivos gobiernos, por cierto) parecerían programadas para reaccionar exclusivamente ante impulsos foráneos y actúan casa dentro con lógicas parecidas a las de las transnacionales: la depredación ambiental y el irrespeto social no están ausentes de sus prácticas" (Acosta 2012). 
el papel que dichas políticas de exportación de commodities $^{22}$ tienen dentro del sistema económico mundial. No extraña, por lo tanto, que el impulso a la extracción de dichas materias primas se produzca en el marco de un cambio radical en el patrón de reproducción capitalista, auspiciado como una dinámica de reacomodamiento de la acumulación como respuesta a la crisis de sobreacumulación crónica que viene afrontando el capital desde la década del setenta (Harvey 2004a y 2004b).

De igual manera, aunque salten a la vista las limitadas repercusiones que hasta el momento ha tenido la crisis financiera en la economía ecuatoriana, no es posible desconocer el importante papel que esta ha cumplido en relación con la entrada de nuevas inversiones provenientes de distintas partes del globo que anteriormente tenían una reducida presencia en el continente. En cuanto a las relaciones con Brasil y China, es claro que Ecuador constituye un mercado en disputa entre estas nuevas potencias y los poderes económicos que históricamente han desplegado todo tipo de estrategias para apoderarse de los bienes naturales del país. No es gratuito, por lo tanto, que dentro de los principales proyectos de explotación minera en Ecuador figure capital chino, así como que la construcción de la Iniciativa de Infraestructura Regional Suramericana (IIRSA) haya tenido uno de los más importantes avances en este país. No obstante, a la luz de los acuerdos económicos a los que han llegado con los Estados Unidos, incluso en lo relacionado con la extracción de recursos naturales en América Latina $^{23}$, pareciera que tanto China como Brasil también se permiten jugar el papel de intermediarias entre las necesidades del "imperio del capital" y los gobiernos antiimperialistas latinoamericanos, incluyéndose entre estos el gobierno de la Revolución Ciudadana. Incluso se podría afirmar que el ingreso de China y Brasil como actores de inusitada importancia en la actual economía ecuatoriana, desplegando dinámicas de acumulación por desposesión para favorecer a sus clases capitalistas - un tipo de accionar en donde anteriormente destacaba la pericia de EE.UU.-, más que entrar en conflicto con los intereses de Estados Unidos, cuenta con su permisividad, debido en cierta medida también a la poca importancia geopolítica que puede representar este pequeño país en términos de recursos naturales - minerales estratégicos, petróleo, agua- o posición militar estratégica, conjetura que razonablemente se puede inferir de los datos aportados por Mónica Bruckmann en el ya citado libro de Atilio Borón.

En lo concerniente a la legitimidad social requerida para desarrollar el proyecto neoextractivista, las políticas de asistencia social emanadas desde el gobierno Correa para la reducción de la pobreza y la desigualdad han cumplido un claro rol de facilitación del acceso del capital transnacional a los recursos naturales del país, disminuyendo las posibilidades de resistencia popular al saqueo

22 Por commodities entendemos aquellos bienes que "no cuentan con ningún valor agregado" $y$ "son utilizados como materias primas para la elaboración de otros bienes." Estos a su vez se dividen en: Energéticos (petróleo, gas natural, carbón), metales industriales (cobre, níquel, zinc, etc.), metales preciosos (oro, plata), agrícolas (soya, palma africana, trigo, maíz, entre otros). Ver Universidad Icesi (2008).

23 Uno de los mejores ejemplos de cómo se diluye el pretendido "antagonismo" entre China y Estados Unidos y lo que esto representa para los intereses de Ecuador, se presenta en la reventa de petróleo ecuatoriano que realiza China, destinando buena parte de este al mercado estadounidense (Olivieri 2013). 
ambiental. Todo esto, considerando las múltiples anécdotas que puede contar el pueblo ecuatoriano de derrocamiento de mandatarios cuando el descontento social se ha salido de las manos del poder oficial.

El triunfo de Rafael Correa es claramente la consecuencia de un amplio apoyo popular a un proyecto que prometía acabar con el modelo neoliberal en el país y recuperar la soberanía nacional frente a los Estados Unidos de Norteamérica -aunque paradójicamente no haya logrado desdolarizar su economía-. Visto someramente, su propuesta no incluye fortalecer ningún tipo de "burguesía nacional" para avanzar hacia un "capitalismo serio o más humano", como sí puede decirse de sus pares latinoamericanos como Lula-Rouseff en Brasil o KirchnerFernández en Argentina. Adicionalmente, la constante reproducción del discurso sobre el socialismo del siglo XXI ha evitado la integración de este proceso político dentro del "neodesarrollismo" teorizado por autores como Claudio Katz. Sin embargo, la puesta en práctica del modelo neoextractivista, aunque no tenga como protagonista directo al viejo imperio que históricamente ha desangrado a los países de su "patio trasero", ni tampoco a una clase dominante autóctona, no conlleva tampoco la concreción de una verdadera alternativa al sistema imperante que mantiene al país andino en una posición periférica en la división internacional del trabajo, más aún si tenemos en cuenta el rotundo fracaso que hasta el momento ha representado, según demuestra Ospina, la no superación del modelo primario exportador, promesa estipulada en el Plan del Buen Vivir.

Si bien no es posible desconocer el punto de quiebre que representó el advenimiento de la Revolución Ciudadana en Ecuador, especialmente en su propósito de asumir la vocería de sectores sociales históricamente excluidos del devenir político y económico, como se evidenció en el proceso de elaboración de la Constitución de 2008, tampoco debe ocultarse el abierto alejamiento que en épocas recientes se ha producido entre la dirigencia de Alianza PAIS y buena parte de su base social, en aras de garantizar la disponibilidad de nuevas fuentes de inversión transnacional ávidas por explotar la riqueza natural del país.

Aunque todavía pueda ser demasiado pronto para realizar predicciones contundentes sobre las perspectivas de la Revolución Ciudadana, su reconciliación o definitivo distanciamiento del movimiento social que permitió su surgimiento, o las posibilidades de una verdadera redistribución de la riqueza en la sociedad ecuatoriana, no es osado sostener que la larga noche neoextractivista no concluirá en ausencia de una clara, decisiva y revolucionaria acción de los pueblos que trascienda los límites de la democracia representativa y que, especialmente, permita la priorización de los valores de uso por encima de los valores de cambio, tanto en la relación de la humanidad con la Naturaleza, como en los distintos aspectos de la vida social.

\section{Referencias bibliográficas}

Acosta, Alberto. «Ecuador ¿un país maniatado frente a la crisis?». Revista Análisis Económico. La crisis internacional y su incidencia en Ecuador, $\mathrm{n}^{\circ} 21$ (enero 2009): 153-182. 
. «Extractivismo y neoextractivismo: dos caras de la misma maldición». En Ecoportal, 2012. [En línea]. http://www.ecoportal.net/Temas_Especiales/ Mineria/Extractivismo_y_neoextractivismo_dos_caras_de_la_misma_maldicion (último acceso: 31 de julio de 2014).

AGN. «Minera china Ecuacorriente entrega 40 millones a Ecuador por regalía anticipada de explotación». Periódico El Mercurio, 27 de diciembre de 2012. [En línea]. http://www.elmercurio.com.ec/362612-minera-china-ecuacorriente-entrega-40-millones-a-ecuador-por-regalia-anticipada-de-explotacion.html (último acceso: 26 de junio de 2013).

Araújo, Alberto. «La minera china Junefield compra un proyecto de oro y plata en Azuay». Periódico El Comercio, 4 de abril de 2013. [En línea]. http://www.elcomercio.com/negocios/minera-Junefield-compra-proyecto-Azuay_0_895110560. html (último acceso: 25 de junio de 2013).

Astarita, Rolando. «Crisis de la tesis de la financiarización». En Rolando Astarita, diciembre de 2008. [En línea]. http://www.rolandoastarita.com/dt-Critica\%20 tesis\%20de\%20la\%2ofinanciarizacon.htm (último acceso: 16 de junio de 2014).

Bellamy, John, y Fred Magdoff. «La burbuja del endeudamiento en los hogares». En La gran crisis financiera. Causas y consecuencias, 41-127. Madrid: Fondo de Cultura Económica, 2009.

Borón, Atilio. América Latina en la geopolítica del imperialismo. Buenos Aires: Ediciones Luxemburg, 2013.

Breda, Tadeu. «Ecuador le apunta al biodesarrollo hacia el 2025». Terra Magazine, 4 de julio de 2009. [En línea]. http://www.ar.terra.com/terramagazine/ interna/o,OI3858002-EI8865,00-Ecuador+le+apunta+al+biodesarrollo+hacia+ el.html (último acceso: 26 de junio de 2014).

Clavero, Bartolomé. «Ley frente a Constitución en el Ecuador: Nueva Ley de Minería». En ¿Hay genocidios cotidianos? y otras perplejidades sobre América indígena, 28-32. América del Sur: IWGIA, 2011. [En línea]. http://www.bartolomeclavero.net/wp-content/uploads/2014/o8/genocidio-cotidiano.pdf (último acceso: 6 de diciembre de 2014).

Comisión Ecuménica de Derechos Humanos. «La intervención minera a gran escala de EcuaCorriente y la desaparición del poblado "San Marcos"». En Observatorio de Conflictos Mineros de América Latina, 29 de mayo de 2014. [En línea]. http://www.conflictosmineros.net/contenidos/12-ecuador/16566la-intervencion-minera-a-gran-escala-de-ecuacorriente-y-la-desaparicion-delpoblado-san-marcos (último acceso: 28 de junio de 2014).

Dávalos, Pablo. «Los movimientos sociales en el posneoliberalismo: de la resistencia a la esperanza». En América Latina en movimiento, 29 de marzo de 2012. [En línea]. http://www.nacionmulticultural.unam.mx/Portal/Central/EDITORIAL/ pdfs/110210_posneoliberalismo.pdf (último acceso: 7 de diciembre de 2014).

Duménil, Gerard, y Dominique Lévy. «Tercera Parte. La ley de las finanzas». En Crisis y salidas de la crisis. Orden y desorden neoliberales, 107-202. México, D.F.: Fondo de Cultura Económica, 2007.

El Ciudadano. «Ecuador inaugura el eje Manta-Manaos». Periódico El Ciudadano, 15 de julio de 2011. [En línea]. http://www.elciudadano.gob. ec/index.php? option=com_content\&view=article \&id=26094: ecuadorinaugura-hoy-el-proyecto-manta-manaos-el-objetivo-futuro-es-competir- 
con-el-canal-de-panama\&catid=40:actualidad\&Itemid=63 (último acceso: 26 de junio de 2013).

Espinosa, Eugenio. «Crisis económica y cambios políticos y sociales en América Latina». En La crisis capitalista mundial y América Latina, 123-144. Buenos Aires: CLACSO, 2012.

Estrada, Jairo. «Elementos de economía política de la política social en América Latina. Reflexiones a propósito de los gobiernos progresistas». En ¿Otros mundos posibles? Crisis, gobiernos progresistas, alternativas de sociedad, 131146. Medellín: Fundación Rosa Luxemburg, Facultad de Ciencias Humanas y Económicas, Universidad Nacional de Colombia, 2012.

FETRALPI. «Iamgold se retira de Quimsacocha». En FETRALPI, 24 de junio de 2012. [En línea]. http://fetralpi.blogspot.com/2012/06/iamgold-se-retira-dequimsacocha.html (último acceso: 25 de junio de 2013).

Gudynas, Eduardo. «Diez tesis urgentes sobre el nuevo extractivismo. Contextos y demandas bajo el progresismo sudamericano actual». En Extractivismo, política y sociedad, editado por Jürgen Schuly, et al., 187-225. Quito: CLAES-CAAP, 2009. [En línea]. http://extractivismo.com/noticias/extractivismoquitoo9. html (último acceso: 24 de junio de 2014).

. «Izquierda y progresismo: la gran divergencia». En América Latina en movimiento, 2013. [En línea]. http://alainet.org/active/70074 (último acceso: 23 de abril de 2014).

Harvey, David. El nuevo imperialismo. Madrid: Akal, 2004a.

. «El "nuevo" imperialismo: acumulación por desposesión». En Socialist Register, 99-129. Buenos Aires: CLACSO, 2004 b.

. Espacios del capital. Hacia una geografía crítica. Madrid: Akal, 2007.

International Monetary Fund. Commodity Market Monthly, 11 de julio de 2004. [En línea]. http://www.imf.org/external/np/res/commod/pdf/monthly/o70114.pdf (último acceso: 25 de junio de 2014).

Jiménez, Carolina. «El territorio latinoamericano como fuerza productiva estratégica. Una aproximación crítica a los procesos de redefinición capitalista del espacio». En La crisis capitalista mundial y América Latina, 265-277. Buenos Aires: CLACSO, 2012.

Katz, Claudio. «Gobiernos y regímenes en América Latina». La haine, 2007. [En línea]. http://www.lahaine.org/katz/b2-img/katzgob.pdf (último acceso: 28 de junio de 2014).

- «América Latina frente a la crisis global». En Crisis capitalista. Economía, política y movimiento, de Jairo Estrada, 139-166. Bogotá: Espacio Crítico Ediciones, 2009.

. «Latinoamérica I: comparaciones y explicaciones de la crisis». La haine, 2010. [En línea]. http://www.lahaine.org/b2-img1o/katz_latl.pdf (último acceso: 28 de junio de 2014).

. Bajo el imperio del capital. Bogotá: Espacio crítico Ediciones, 2011.

La Hora. "La megaminería se materializa en Ecuador tras proyecto "Mirador"». Periódico La Hora, 5 de marzo de 2012. [En línea]. http://www.lahora.com.ec/index. php/noticias/show/1101293578/- 1/La_megaminer\%C3\%ADa_se_materializa_en_ el_pa\%C3\%ADs_html\#.Ub_R2pzNnGB (último acceso: 24 de junio de 2012). 
Lucarelli, Stefano. «La financiarización como forma de biopoder». En La gran crisis de la economía global. Mercados financieros, luchas sociales y nuevos escenarios políticos, de Stefano Fumagalli et. al, 125-148. Madrid: Traficantes de sueños, 2009.

Marx, Karl. El Capital, Tomo I. México, D.F.: Fondo de Cultura Económica, 1999. El Capital, Tomo III. México, D.F.: Fondo de Cultura Económica, 1959.

Mena, Paúl. «Minería, agua y tierras enfrentan a Correa e indígenas en Ecuador». $B B C$ Mundo, 22 de marzo de 2012. [En línea]. http://www.bbc.co.uk/mundo/ noticias/2012/03/120322_correa_disputa_indigenas_cr.shtml (último acceso: 24 de junio de 2014).

Ministerio de Recursos Naturales No Renovables. «El Estado ecuatoriano garantiza la continuidad del proyecto Fruta del Norte, a través de la transferencia de acciones de Kinross Gold Corp a Fortress Minerals Corp». En Ministerio de Recursos Naturales No Renovables, 22 de octubre de 2014. [En línea]. http:// www.recursosnaturales.gob.ec/el-estado-ecuatoriano-garantiza-la-continuidaddel-proyecto-fruta-del-norte-a-traves-de-la-transferencia-de-acciones-de-kinrossgold-corp-a-fortress-mineral-corp/ (último acceso: 9 de diciembre de 2014).

Olivieri, Angelo. "China compra el petróleo de Ecuador (y lo vende a Estados Unidos)». América en el Mundo, 5 de diciembre de 2013. [En línea]. http:// www.americaenelmundo.com/china-compra-el-petroleo-de-ecuador/ (último acceso: 30 de marzo de 2014).

Ospina, Pablo. «Promesas temporales. Cambio del régimen de acumulación en Ecuador, promesas y realizaciones de la Revolución Ciudadana». En ¿Otros mundos posibles? Crisis, gobiernos progresistas, alternativas de sociedad, $113-$ 130. Medellín: Fundación Rosa Luxemburg, Facultad de Ciencias Humanas y Económicas, Universidad Nacional de Colombia, 2012. [En línea]. revistas.luz. edu.ve/index.php/cp/article/viewFile/10484/10146 (último acceso: 24 de junio de 2014).

, y Rickard Lalander. «Razones de un distanciamiento político: el Movimiento Indígena ecuatoriano y la Revolución Ciudadana». Revista del Observatorio Social de América Latina, Vol. XIII, n 32, (noviembre 2012): 117-134. [En línea]. http://biblioteca.clacso.edu.ar/clacso/osal/20120927103642/OSAL32.pdf (último acceso: 28 de junio de 2014).

Portal Minero. «Avanza exploración de proyecto Panantza-San Carlos en Ecuador». En Minga Service S.A., 26 de mayo de 2011. [En línea]. http://www.mingaservice.com/web/inicio/304-avanza-exploracion-de-proyecto-panantza-sancarlos-en-ecuador.html (último acceso: 25 de junio de 2013).

Portal Puerto de Manta, Ecuador. «En Ecuador se ratifica construcción del Puerto de Aguas Profundas en Manta». Mundo Marítimo, 23 de noviembre de 2012. [En línea]. http://www.mundomaritimo.cl/noticias/en-ecuador-se-ratificaconstruccion-del-puerto-de-aguas-profundas-en-manta (último acceso: 24 de junio de 2013).

Ramírez, Franklin. «Desencuentros, divergencias, polarización (y viceversa) el gobierno ecuatoriano y los movimientos sociales». Revista Nueva Sociedad, $\mathrm{n}^{\circ}$ 227, (mayo-junio 2010): 83-101. [En línea]. http://www.nuso.org/upload/articulos/3698_l.pdf (último acceso: 15 de junio de 2014). 
Sacher, William, y Acosta, Alberto. La minería a gran escala en Ecuador. Análisis y datos estadísticos sobre la minería industrial en el Ecuador. Quito: Ediciones Abya Yala, 2012.

Sosa, David. «Empresa canadiense minera Kinross se retira de Ecuador». Martí Noticias, 11 de junio de 2013. [En línea]. http://www.martinoticias.com/content/article/23354.html (último acceso: 24 de junio 2013).

Stolowicz, Beatriz. "América Latina hoy: la estrategia conservadora posneoliberal para la estabilización capitalista». Escenarios XXI. Revista de relaciones internacionales. (marzo-abril 2011). [En línea]. http://escenarios21.net/americalatina-hoy-la-estrategia-conservadora-posneoliberal-para-la-estabilizacion-capitalista/ (último acceso: 28 de junio de 2014).

Universidad Icesi. "Commodities». Consultorio de Comercio Exterior-Universidad Icesi, 12 de septiembre de 2008. [En línea]. http://www.icesi.edu.co/blogs/ icecomex/2008/09/12/commodities/ (último acceso: 26 de junio de 2014).

Vega, Renán. «Crisis de la civilización capitalista: mucho más que una breve coyuntura económica». En Crisis capitalista. Economía, política y movimiento, de Jairo Estrada, 61-101. Bogotá: Espacio Crítico Ediciones, 2009.

Zibechi, Raúl. Brasil potencia. Entre la integración regional y un nuevo imperialismo. Bogotá: Ediciones Desde Abajo, 2012.

\section{Entrevistas}

Entrevista a Walden Bello, profesor de ciencias políticas y sociales en la Universidad de Filipinas (Manila), miembro del Transnational Institute de Amsterdam y presidente de Freedom from Debt Coalition. «Todo lo que usted quiere saber sobre el origen de esta crisis pero teme no entenderlo». Sin permiso, 5 de octubre de 2008. [En línea]. http://www.sinpermiso.info/textos/index. php?id=2097 (último acceso: 31 de julio de 2014).

Entrevista a Robert Brenner, miembro del Consejo Editorial de SINPERMISO, director del Center for Social Theory and Comparative History en la Universidad de California-Los Ángeles. «Un análisis histórico-económico clásico de la actual crisis». Sin permiso, 22 de febrero de 2009. [En línea]. http://www.sinpermiso.info/textos/index.php?id=2385 (último acceso: 27 de junio de 2014). 